

\section{Farrebique o la paradoja del realismo}

\section{ANDRÉ BAZIN}

crófono, eran mil veces preferibles a cualquier postsincronización. Y el resultado está aquí.

El film quizá no sea perfecto, pero el público siente muy bien que le aporta algo nuevo, algo que esperaba y que nunca conseguía: las cosas tal como son. Entonces el público está contento y una alegría profunda y sincera lo invade al reconocer a sus amigas: las cosas.

Un crítico cinematográfico, sin duda demasiado distinguido, se queja por escrito de haber visto la bosta de las vacas, la lluvia caer, las ovejas balar, los campesinos hablar su dialecto, a causa de lo cual él llega a detestar la vida en el campo. Por eso mismo uno puede detestar a los críticos de cine.

Farrebique es un film apasionante como la vida, cautivante como esos recuerdos que vienen de la infancia, traídos por un olor o una palabra. Las imágenes de Farrebique tienen el encanto de algo que es reencontrado. Por más que no le guste al señor Jean Fayard, que seguramente nunca pisó una chacra. [El crítico Jean Fayard, en la revista Opera, escribe: «ni siquiera es un documental, ya que no nos enseña exactamente nada» o «aquí todo es pobre, limitado, carente de imaginación, privado de poesía, estirado al máximo»]. Hay más cine — del verdadero- en mostrar esa bosta de vaca en un establo de la región de Rouergue, que en veinte films pretendidamente «realistas», donde la realidad está secretamente ausente. El placer del público de Farrebique se parece al de los primeros espectadores del cine, que se maravillaban frente a los films de Lumière, y que exclamaban, frente a la imagen parpadeante de las hojas de un árbol: «ise mueven!». A su manera, Georges Rouquier reinventa el cine.
La posición elogiosa de los partidarios de Farrebique, la mala fe de Henri Jeanson y de los escasos "antiFarrebique», que han asumido en la prensa una posición polémica, ocultan en el fondo una gama de opiniones más matizadas cuando esas opiniones en lugar de ser públicas se hacen en privado. Si excluimos dos o tres juicios imbéciles sobre la banalidad del realismo de Farrebique, todos están de acuerdo en reconocer el interés excepcional del film; las divergencias aparecen solamente cuando se trata de apreciar la importancia relativa de ciertas debilidades en una obra que no es en todos los aspectos perfecta. Se le puede reprochar por ejemplo, el haber parcialmente traicionado sus propósitos documentales al haber descuidado las relaciones económicas de la chacra con el pueblo. La parte «poética» del film puede también ser diversamente apreciada. Ese es, me parece, el aspecto más discutible, aunque ciertos fragmentos, como la llegada del invierno, estén perfectamente logrados, y aun cuando la secuencia del entierro pertenezca ya a la antología de los grandes entierros cinematográficos. Pero las interpretaciones personales, las transposiciones poéticas, a las cuales Rouquier se arriesgó a lo largo de su film, pueden recibir juicios de valor a los cuales escapa lo esencial de la obra.

Debemos distinguir en Farrebique lo que pertenece a la sensibilidad personal del poeta - de un gusto más o menos justo- del propio principio de la obra, de ese descubrimiento inicial y definitivo del que surge su profunda originalidad. Me apresuro a aclarar que considero a Rouquier un poeta, y que la distinción puramente lógica que quiero establecer no pretende de ninguna manera minimizar todo lo que debe Farrebique a la sensibilidad de su autor. Simplemente 
me parece importante no confundir las cualidades relativas y discutibles, con un descubrimiento objetivamente irrefutable, y del cual el cine puede obtener beneficio en dominios muy distintos al de lo «bucólico». Se podría decir que el valor de Farrebique es menos estético que moral. Había que tener, para conducir exitosamente esta aventura, algo más que el valor de intentarla: una voluntad de permanecer en todo momento, fiel a su intención inicial. Farrebique es una empresa ascética cuyo objeto es despojar la realidad de todo lo que no le pertenece, y en particular del parasitismo del arte. La empresa valió la pena. Hacía falta más imaginación y perseverancia que lo que se imagina, para descubrir sus reglas y observarlas sin desviarse. Algunos dirán - ya se ha hecho, desgraciadamente- que no vale la pena tanto esfuerzo para llegar finalmente al punto de partida.

«He visto, escribe en resumen Jean Fayard, durante una hora y media las vacas en medio de la bosta, los campesinos comer, la lluvia caer, el barro pegotearse a los zapatos...». Acontecimientos tan poco significativos, le parecen a Jean Fayard indignos de figurar en una obra cinematográfica. Jean Fayard piensa que es más simple ir al campo, y más generalmente, que no hace falta ir al cine para ver las cosas tal como son.

Antes de responder a esta objeción quisiera hacer notar que el cine no deja de pretender mostrarnos las cosas tal como ellas son. «En el cine, dice la vieja campesina en el Diario de Jules Renard, se cree siempre que eso que se ve es cierto». Con excepción de algunos films que han sistemáticamente tratado de escapar al realismo del decorado, el cine, aun el fantástico o el mágico, fundamenta lo esencial de su eficacia en la verosimilitud material. La objetividad técnica de la fotografía se prolonga naturalmente en su objetividad estética. Es así como la historia del decorado desde hace treinta años, después de la herejía del expresionismo, muestra una vuelta continua al realismo. Marcel Carné no ha hecho construir por Trauner, para Las puertas de la noche (Les portes de la nuit), una estación de subterráneo de fantasía, sino una parecida lo más posible a la real: no falta ni un barrote de una reja. El rol del arquitecto decorador del cine moderno consiste en inventar para un guión dado, un decorado lo más verosímil posible, el que puede aportar la ayuda dramática máxima, sin duda, para colocar la intriga en un contexto de verosimilitud. El cuarto de Gabin en "Le jour se lève» es una obra maestra de precisión documental al mostrar dónde vive un obrero soltero en los suburbios de París.

Que no se venga entonces a acusar Farrebique de exceso de realismo, porque, si no, se debería acusar a todo el cine.

Si el crítico de Farrebique me objetara ahora que el realismo general del cine le permite acceder a la esfera del arte solo en la medida en que es artificial, concertado, reconstruido, elegido, y no por sí mismo, sino como elemento de la obra dramática a la que sirve, me permitiría hacer otra observación.

¿Es tan seguro que esta subordinación al proyecto estético (dramático o de otro tipo) que la trasciende, no haya lentamente falseado nuestro sentido de la realidad en el cine? Hay muchos films llamados realistas, del tipo «hechos policiales» 0 «tranche de vie». Incluso hay films sobre la vida en el campo. ¿Por qué Farrebique parece el patito feo en un grupo de pollitos? Ahí es donde reside el rasgo genial de Rouquier, su gran descubrimiento. Comprendió que la verosimilitud había ocupado poco a poco el lugar de la realidad, que la realidad se había disuelto en el realis- 

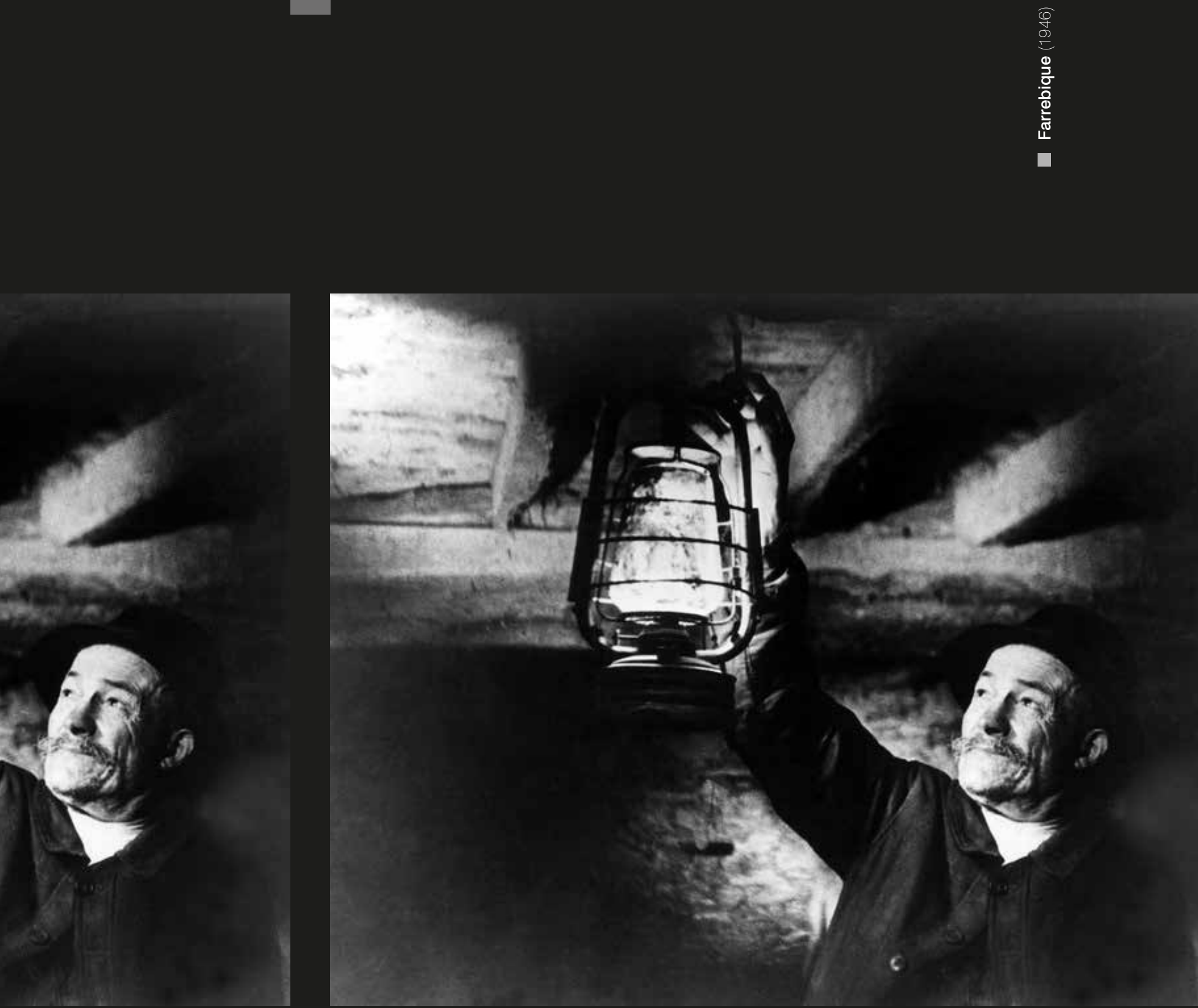
mo. Emprendió entonces laboriosamente la tarea de descubrirla, de llevarla a la luz, de hacerla aparecer, desnuda, del pozo del arte.

Algunos acusan a Farrebique de ser fea. Sus hombres y mujeres es cierto que no son bellos. Ese paisaje de la región de Rouergue no tiene grandeza. El lugar donde viven está sucio, y no tiene el pretexto del estilo. La plaza del pueblo que vemos el domingo a la mañana a la entrada y a la salida de la misa es de una gran banalidad. Francia es un país donde abundan los pueblos cuyo aspecto pintoresco histórica y geográficamente hubieran suministrado a Rouquier una belleza intrínseca y justificada por el interés documental del film. El crítico Henri Jeanson se convierte en un moralista y un patriota al deplorar la imagen que Farrebique va a dar en el extranjero de la vida en el campo francés. «Viven como animales, no practican ninguna higiene y se expresan en un francés aproximativo», - supongo que Jeanson se refiere al dialecto que se habla en esa región.

Pero es demasiado claro que Rouquier no podía llevar a cabo su proyecto con una materia cuya belleza hubiera sin duda falseado la reacción química de la cámara.

Un bello paisaje, una pequeña iglesia romana, alguna diversión folklórica nos hubiesen alejado de la naturaleza, del pueblo, de esta asamblea de jóvenes cuyos placeres y juegos se limitan a una semi-borrachera los domingos a la tarde, en un salón del bar lleno de moscas. Sin horror y sin pintoresquismo, la realidad de Georges Rouquier se sitúa en una zona neutra que solicita la menor admiración o piedad posible. Esta realidad no es nada más que ella misma, el tipo mismo de realidad sobre la cual el artista no tiene nada que decir. Es sin embargo sobre ella que se centra la atención de Rouquier, y es sobre ella que la cámara opera esta misteriosa y paradójica operación fotográfica al cabo de la cual logramos simplemente conocer la realidad.

Y aquí me refiero al público. Ese famoso público que debería aburrirse tanto como Jeanson. Confieso que por haber visto dos veces Farrebique en proyecciones privadas, temía, a pesar de mi admiración, que el público se aburriera. Me parece que incluso Rouquier no estaba seguro de lo contrario. Pero tuve que ver el film en medio de los espectadores que habían pagado su entrada (y que no eran millonarios) para darme cuenta que, sin historia y sin vedetes, este film rezumaba un encanto casi demagógico, y que el público era profundamente sensible al placer de simplemente reconocer las cosas. Nosotros habíamos visto el campo cientos de veces en el cine, pero siempre servía de decorado para los actores o pretexto para la habilidad del fotógrafo. Incluso la nieve, cuando no era ácido bórico, era un elemento pictórico o dramático (como en La sinfonía pastoral), las ovejas llevaban en el cuello la cinta imaginaria de la intriga. En Farrebique, por el contrario, la realidad no es nunca completamente subordinada al relato $o$ al arte, existe antes que nada por ella misma. En el admirable poema del invierno, el montaje de Georges Rouquier no eleva nunca las cosas a la abstracción del símbolo (hay que reconocer que tiene menos éxito en la secuencia de la primavera). Los cables telegráficos cubiertos de escarcha, el perro que corre en la nieve, el hielo del camino marcado por los zapatones del hombre, no son más que hechos, banales y múltiples, pero no generales. Rouquier les preserva su singularidad total. Tomemos por ejemplo la fogata. Hemos visto muchas en el cine, e incluso mejor 
fotografiadas que esta. En Goupi mains rouge [film de 1943 dirigido por Jacques Becquer] un personaje atiza las brasas tal como hace el abuelo de Farrebique. Solo que el fuego del abuelo es una verdadera fogata, y las llamas surgen no cuando el asistente lo pide, y todos se dan cuenta, sino cuando los troncos las producen. Aquellos que han tenido familiaridad con el fuego, han reconocido por primera vez en la pantalla, el misterio singular e innombrable de las llamas y de la leña. El público no se equivoca, reconoce el charco embarrado del camino que ensucia los zapatos del habitante de la ciudad que está en vacaciones en la granja del cuñado, reconoce a la tía, que atiende la tienda o el quiosco en el pueblito del Centro o del Sudoeste de Francia, del cual sus padres eran originarios, reconoce el parque de atracciones, reconoce toda su experiencia de campesino frustrado. Reconoce ese mundo un poco ridículo y nostálgico que, confusamente, tiene la impresión de haber traicionado, ese mundo de tierra, hombres y animales cuya memoria conserva en los recuerdos de la infancia y de las vacaciones. Sin historia, o tan poca, sin vedetes, sin actores, nada más que una realidad que cada uno, en el secreto de su mala o buena con- ciencia, reconoce personalmente. «Miren», decían los primeros espectadores del Cinematógrafo Lumière, señalando las hojas de los árboles, «!miren, se mueven!». Cuánto camino recorrido por el cine desde esos tiempos heroicos en que las multitudes estaban satisfechas por la restitución aproximativa del movimiento de las hojas a causa del viento. Y sin embargo, más allá de los cincuenta años de realismo cinematográfico, en un plano de realidad sin duda muy superior, hacía falta un poco de genio para restituir al público esta alegría simple y elemental que el cine novelesco y dramático ya no proporcionaba: la alegría del reconocimiento.

Por eso, a pesar de sus defectos, de cierto esteticismo paradójico y un poco anacrónico, de algunas torpezas en el relato, de un sentido poético evidente pero desigual, considero Farrebique como un verdadero acontecimiento. Uno de los muy raros films franceses que, con Espoir de Malraux, evidencia que era necesaria la revolución realista que el cine debía tener, revolución que acaba de estallar en Italia, y que desde hace dos años los cineastas italianos desarrollan de manera tan perfecta que uno tiembla pensando que quizá anuncie su academicismo. 